\title{
Trend Analysis of Mass Music Teaching under the Background of Quality Education
}

\author{
Kegang Lu \\ (Moscow School of Arts, Weinan Normal University,Weinan 714099, PR China)
}

\begin{abstract}
Keywords: Mass music; quality education; Education and teaching
\end{abstract}
\begin{abstract}
In recent years, the cultural level and aesthetic ability of our people have been significantly improved, accompanied by an increase in the ability to enjoy music for the general public. Since ancient times, music is an important way to help people to express their feelings and ease their body and mind in their daily life. In the context of popular music culture today, music media and social music activities have made rapid progress. Music has also gained the support of the general public from entering into the classroom. Quality education pays attention to human's healthy individuality and helps to improve students' comprehensive quality. Under the guidance of quality education theory, the reintegration of music teaching resources is the core of improving the quality of music teaching in colleges and universities. It not only help to achieve the sustainable development of college music teaching, but also for the community to cultivate high-quality professional music talent. Starting with the discussion of related concepts, this paper analyzes the importance and requirements of music education from the perspective of quality education and explores the development strategies of popular music education from the perspective of quality education.
\end{abstract}

\section{Connotation of Mass Music Teaching under Quality Teaching}

First of all, the music education under the concept of quality education must be a general education for all students. This is because the fundamental purpose of quality education is to enhance the quality of the whole people. Under the guidance of the concept of quality education, music education must be distinguished from outdated excellence education. All students should be educated to ensure that all students enjoy the right to education so that all students can enjoy the influence of music and arts. Second, the music education under the concept of quality education must continue to promote the process of students' all-round development. Music education can strengthen the overall quality of students, enabling students to enhance their comprehensive literacy skills on the basis of strengthening their artistic quality. Therefore, the school music education must attach importance to the cultivation of music literacy, enabling students to form the correct values through music education, thus promoting the all-round development of students. Finally, the music education under the conception of quality education must reflect the students' subjectivity. Based on the students, in accordance with the students' actual music needs, the appropriate contents and methods of music education should be attached importance to students' enthusiasm and initiative in music learning. Build a harmonious, progressive music education environment, enabling students to learn music in a good learning environment.

\section{The Characteristics and Development of Mass Music Culture}

\section{The Characteristics of Popular Music Culture \\ Popularization}

This is because the source of mass music is the mass environment, the emotion and spiritual culture contained in are what the general public possesses. The content and form of the song are not restrained by tradition, on the contrary, they are mass and free. It is also because mass music possesses the characteristics of popularization. Therefore, all sectors of society also widely recognize and promote popular music. With the help of mass communication, more people can enjoy popular music. 


\section{Liberalization}

Mass music culture does not constrain the creator or content creation, and even the effect and the impact have great freedom. Moreover, everyone has the right to enjoy music and will not form any kinds of restraint on the freedom of music due to such factors as identity, environment and time. Although popular music styles vary widely, liberalized mass music gives everyone the power of choice and freedom to choose their favorite music.

\section{Diversification}

The pluralism of mass music culture can be expressed on the following three levels: form diversity; expression diversity; media diversity. Nowadays, as we are in an era of rapid development of information technology, we do not have to rely on musical instruments to enjoy music. Many of the common tools in life can also create music. For example, the use of glass to create music, combined with water boiling sound, upstairs, wind chimes and other daily life voice to create music, such music is more respected. In addition, the era in which people are nowadays is the era of diversification. Not only the music field tends to be pluralistic, but also diversified in all walks of life and is further explored and used.

\section{The Importance of Mass Music Teaching in Quality Teaching}

\section{Moral Quality Cultivation in Music Teaching}

The students' outlook on world and life has not yet matured, and then it is required that school education play the role of guidance and cultivation. From the current thinking characteristics of students to analyze, quick thinking, curiosity heavier, and new things can accepted in a very short time. However, the notion of ideas is immature, which makes their ideological ideas extremely easily eroded by negative or unhealthy thoughts, which in turn leads to non-diffusive phenomena. However, music education can make the students 'ideological and moral qualifications to a certain degree to be strengthened, and with the help of musical works, the students' ideological consciousness can be guided in their own ways, so that their ideological realm is promoted. This is mainly due to the very close relationship between music and thought. With the help of music, creators can express their ideas and emotions, and can also make moral and ethical behaviors be regulated in this kind of thoughts and emotions. Moreover, positive and up-tempo music can help students work hard.

\section{Cultural Quality Cultivation in Music Teaching}

First of all, students can get some reinforcement through music education. In other words, music education can promote the process of cultivating students' image thinking, and make students have a great balance in brain functions, and their intelligence will be virtually improved. Secondly, music education can make students' imagination greatly improved, enabling students to describe the content of music in their mind when listening to music, which not only can deeply understand the content of music, but also to a large extent on the strengthening of students' intelligence. Finally, music education can greatly cultivate students' music appreciation ability and improve their music literacy. In other words, music education can help students to form the correct aesthetic concept, which in turn enables the students' artistic accomplishments to be greatly strengthened.

\section{Psychological Quality Cultivation in Music Teaching}

First of all, music education can show students the life and essence of art in an all-round way and continuously enhance students' music experience so that students can feel the encouragement and support at the emotional level while enjoying music, thereby helping students to form healthy emotions. Secondly, music education can make use of the way of enjoying music, making the innermost impulsiveness of students get great restraint, guiding the students to establish the correct emotional orientation and making the students' minds get a great purification. In addition, melodic, rhythmic music can make people maintain a comfortable, exciting emotions; and heated majestic music can make people a passionate state; and sad music can enable people immersed in melancholy sadness. It also shows that the music can largely affect people's emotions. Students can combine their own actual state of life and choose the music which can guide them to stay healthy and positive. 


\section{Interpersonal Communication Quality Cultivation in Music Teaching}

First of all, music education regards the achievement of civilization as the content of education, which can greatly enhance students' understanding of civilization and make the students' minds purified and their personality greatly improved. In other words, there are far-reaching historical and cultural on music rhythms, lyrics, harmony and so on. Studying music allows students to gain an in-depth understanding of the history of music and arts so as to enable students to gain a better understanding of the development of civilization. Second, music education can improve students' communicative competence. In other words, music education can use the way of collective participation to strengthen students' collective spirit and sense of team.

\section{Problems Existing in Mass Music Teaching under the Background of Quality Education}

\section{Lack of Practice}

As far as class planning is concerned, music lessons are usually one-week lessons. Some art-major students may have slightly more music lessons a week. However, for most students, there are too few classes in music lessons and it is almost impossible to have a full teaching of music in so few classes. Many students do not have a solid foundation of music, and because too few classes, the music class is usually negligent, teachers and students do not attach importance to music teaching, which makes music teaching has been greatly affected, music eventually evolved into a simple "teaching sing song. "

\section{Inaccuracy on Students Perception}

The music lessons do not require exams or homework, and music seems not so important compared to other compulsory subjects. And because the school's teaching method is mainly "exam-oriented education", emphasis on academic performance, but neglect deputy section, which also largely affected the music faculty, usually a music teacher taught several classes on music lessons.

\section{Improvement on Teaching Content}

Nowadays, the reform of teaching contents in various disciplines has been continuously promoted. However, the teaching of music is still backward. The teaching materials are not updated. Many songs on the textbooks are old songs, and the students do not resonate with these songs. Some students think these songs are no longer fashionable and they are not willing to learn. They have already resisted music teaching in their hearts and lack sufficient interest in music class. In terms of teaching content, music teaching is basically singing songs, there is no in-depth narration on music knowledge, theory analysis and music skills. The content of teaching has been very backward, and do not have substantial content to cultivate music, which is very difficult for music curriculum perfection and optimization task.

\section{Development Strategy of Mass Music Teaching under the Background of Quality Education}

\section{Emphasis on the Combination of Theory and Practice}

Theoretical knowledge can make students systematically understand music, and can pay more attention to the study of music course after deeply understanding related music theory, making music an important discipline that requires thinking and memory. In addition, practice exercises should be carried out a lot. Since there are very few classes in music in junior high school, we should pay attention to the combination between theory and practice when carrying out music teaching. After a certain understanding of the relevant theoretical knowledge, the students can improve their musical level through certain practice. This requires the teacher to have a certain understanding of the student's music level and to teach effectively according to the student's musical level. Strongly targeted teaching allows students to concentrate fully on music classes and actively explore music. In the classroom, students can continue to mobilize the enthusiasm for learning music, which makes them more urgently to recognize the music, understand the music. So the teacher's teaching can be more effective. 


\section{Improvement on Teachers Professional Quality}

Teachers' professional qualities will greatly affect students' learning outcomes. Teachers with excellent teaching ability usually can make students have a great interest in a subject. Therefore, in the process of music teaching, we must pay attention to the cultivation of teachers' quality. At this level, first of all, we should continue to upgrade the teaching staff, introduce more teachers with strong professional qualifications, and conduct rigorous pre-service training so that all teachers can master the key points and techniques of music teaching. And, after formally starting teaching, schools should pay attention to music teaching, which in turn enables teachers and students to value music. The school regularly inspects the music teaching situation, and music course also should be the examination subject.

\section{Teaching Based on the Students Actual Level}

The actual level of students will greatly affect the effectiveness of post-teaching. If the students do not have a sound foundation for their music and the teacher's teaching content is too specialized, which will make it impossible for the students to keep up with the progress of the course and will gradually become less interested in music and will not even be willing to learn. It will greatly affect the teaching effectiveness. In view of this, at the beginning of the semester, teachers can gain a deeper understanding of the basic level about students music through written tests or oral exams. The teacher assess the students according to the actual situation, and then combines the overall situation of the class, and takes the results of the evaluation as a reference for the lesson preparation.

\section{Enriching the Form of Music Quality Education by Various Information Media Resources}

Nowadays, the quality education of music should train all aspects of students' quality. Only by relying on the traditional knowledge, the quality of music education can not meet the needs of today's social development. Instead, it should constantly enrich the forms of education and enhance the quality of students. Newspapers, radio, television, Internet and other information media tools have been closely linked with students' daily life. We should correctly guide students' ideas and lives with these information media tools. The Internet is an important measure to enhance the quality of students. Students can not only find the information they need on the Internet, but also can obtain the music material they want through the use of the sound and video on the Internet, thus making the music knowledge and skills learning easier. And the information on the Internet has basically covered all the music material you want, which makes it even easier to enhance the quality of students. In the knowledge-based economy, the efficiency of the use on resources is one of the decisive factors in the quality and level of higher education. The basic content of higher education is teaching resources. Teachers should pay attention to the re-integration of teaching resources, standing on the level of quality education, keeping pace with the development of the times, and following the principles and laws of higher education to scientifically reset teaching resources and rationally integrate the high-quality resources, which make the resource utilization can be greatly improved.

\section{Conclusion}

Mass music culture has become one of the mainstream culture of contemporary music. Starting from the general public and returning to the public, it is a music culture full of popular flavor. Its freedom and diversity has also been welcomed by more and more people. In such a music environment, the teaching of music faces some problems, including the lack of practice in music, the lack of students' awareness of music lessons and the need for improvement in teaching content.

\section{Acknowledgements}

Fund Project: This work was financially supported by Scientific Research Program of Weinan Normal University(No.2017JYKX008) and Basic Research Projects of Weinan Technology Bureau(No. 2017JCYJ-2-5) 


\section{References}

[1] Ha Rui. Integration of College Music Teaching Resources Facing Classroom Teaching [J] .Journal of Tsinghua University, 2015 (5): $16-19$.

[2] Zhu Huaqin. University Music Curriculum Resources School - based Development Strategy [J]. University Theoretical Front, 2016 (1): 21 -23.

[3] Xue Guangzhong, Zhang Liangzeng. Development and integration of curriculum resources -Into the New Curriculum for Rural Music [J]. Chinese Higher Education, 2013 (8): 31 -34.

[4] Fan Yinli. University Music Education and Ideological Quality Training [J]. Higher Education Research, 2015 (11): 18-21.

[5] Feng Xiaoli. University Public Music Education Curriculum Conception [J]. Educational Development Research, 2015 (4): 46 -49.

[6] Zhang Xiaolei. Research on College Students' Music Quality Education Based on Innovative Thinking [J]. Chinese Higher Education, 2015 (2): 39 -41.

[7] Kou Dongquan, Liu Zhi. Creative Thinking and Training [J] Guangxi Normal University, 2015 (09): 40-55.

[8] Zhao Xing. On the Importance and Significance of Developing Music Quality Education in Colleges and Universities[J]. Beauty and Times, 2015 (01): 40-50.

[9] Li Rong. On the Role of Music Education in Students' Ideological and Political Education [J]. Journal of Guangdong University of Technology (Social Science Edition), 2015 (08): 44-45.

[10] Liu Yifei. Problems and Reform Ideas of Music Education in Primary and Middle Schools in China [J]. Culture and Education Monthly, 2015 (25): 35-40.

[11]Liu Aixiang. On the Role of Music Education in Students' Quality Education [J]. Journal of Shengli College, China University of Petroleum, 2015 (01): 100-105.

[12] Hou Shusuo.Different Education Views in School Music Education: Differences between Professional and Non-professional in School Music Education [J]. Jining Teachers College, 2015 (02): 44-50.

[13]Liu Bingguo. Research on Teaching of Junior Middle School Music under the Background of Mass Music Culture [J] .English Reading and Writing, 2015,46: 27.

[14] Tang Yingqing. Analysis of Junior Middle School Music Education in the Context of Mass Music Culture [J] .Art Fashion, 2014,08: 258.

[15] Su Chenxi.Teaching and Teaching of Junior Middle School Music Education under the Background of Popular Music and Culture [J]. Talent, 2015,36: 93. 